\title{
Do YouTube às narrativas e (des)encontros com culturas juvenis no dezembro vermelho 2020
}

Felipe Aurélio Euzébio ${ }^{1}$ Leonardo Silva ${ }^{2}$ Juliana Ribeiro de Vargas ${ }^{3}$

\begin{abstract}
Resumo:
Neste artigo buscamos analisar algumas das comunicações do "dezembro vermelho", ou "dia mundial de combate à HIV/Aids" veiculadas na plataforma de compartilhamento de vídeos YouTube no ano de 2020. Selecionamos cinco do que chamamos de iniciativas influenciadoras-canais, vídeos e seus respectivos niveis de engajamento - publicadas entre os dias 27 de novembro e 7 de dezembro do respectivo ano. Assim, com o objetivo de realizar uma análise cultural descritiva, entrelaçada às narrativas veiculadas sobre HIV/Aids na plataforma e pondo em evidência discussões sobre pedagogias da prevenção, as iniciativas foram aglutinadas para este estudo de acordo com os formatos/ linguagens empregadas em cada vídeo, sendo elas (a) Campanhas; (b) As experiências do EU; (c) $O$ humor e os memes. Para tal objetivo, também foram utilizados de marcadores conceituais, como engajamento, solidariedade e empoderamento, de forma a investigar os sentidos empreendidos junto às multiplicidades, tanto daquilo que é característico das linguagens utilizadas no YouTube, quanto às especificidades dos contextos culturais nos quais as iniciativas estão inseridas.
\end{abstract}

\section{Palavras-chave:}

Dezembro Vermelho. HIV/Aids. Culturas Juvenis. Youtube. Pedagogias da Prevenção.

\section{From Youtube to narratives and (dis)encounters with youth cultures in the red December 2020}

Abstract: In this paper we seek to analyse some of the 'red december' or 'world AIDS day' communications, aired on the video-sharing platform youtube in 2020. We selected five of what we call influencing initiatives-channels, videos and their respective levels of engagement-published between november 27 th and december 7 th of the respective year. Thereby, in order to perform a cultural descriptive analysis, intertwined with the narratives about HIV/Aids aired on the platform and highlighting the discussions about prevention pedagogies, the initiatives were agglutinated according to the used format/lan-

1 Graduado em Ciências Sociais, Mestrando em Antropologia. E-mail: felipe.aurelio197@hotmail.com. ORCID iD:http://orcid.org/ 0000-0002-8126-8222.

2 Graduando em Ciências Sociais. E-mail: leo1995nh@gmail.com. ORCID iD: http://orcid.org/0000-0002-8543-2114.

3 Doutora em Educação, Pesquisadora e Professora Adjunta do Programa de Pós-Graduação em Educação da Universidade Luterana do Brasil (PPGEDU/ULBRA). E-mail: juliana.vargas@ulbra.br. ORCID iD: http://orcid.org/0000-0002-2959-7889. 
guages in each video, corresponding to (a) Campaigns; (b) The experiences of the SELF; (c) The humor and the memes. In that perspective, conceptual marks such as engagement, solidarity and empowerment were used, seeking to inquire the meanings engaged along the multiplicities, as much of what is characteristic of youtube languages as the specificities of the cultural contexts in which the initiatives are inserted.

Keywords: Red December. HIV/Aids. Youth Cultures. Youtube. Prevention Pedagogies.

\section{Del Youtube a las narrativas y (des) encuentros con las culturas juveniles en el diciembre rojo 2020}

Resumen: En este artículo buscamos analizar algunas comunicaciones del 'diciembre rojo' o 'día mundial de la lucha contra el VIH/SIDA' transmitidas en la plataforma de presentación intercambio de videos de Youtube en 2020. Seleccionamos cinco de lo que llamamos iniciativas influyentes: canales, vídeos y sus respectivos niveles de participación, publicados entre 27 de noviembre y 7 de diciembre del año respectivo. Así, para realizar un análisis cultural descriptivo, entrelazado con las narrativas transmitidas sobre el VIH / SIDA en la plataforma y destacando las discusiones sobre las pedagogías de prevención, las iniciativas para este estudio fueran reunidas según los formatos / lenguajes utilizados en cada video, a saber (a) Campañas; (b) Las experiencias del YO; (c) El humor y memes. Para alcanzar tal intento, también se utilizó marcadores conceptuales, como el comprometimiento, la solidaridad y el empoderamiento, con el fin de investigar los significados asumidos con las multiplicidades, tanto de lo característico de los lenguajes utilizados en YouTube, como de las especificidades de la contextos culturales en los que se insertan las iniciativas.

Palabras clave: Diciembre rojo. VIH/Sida. Culturas juveniles. Youtube. Pedagogías de Prevención.

\section{Introdução}

A eclosão da pandemia de covid-19 já é um dos acontecimentos sanitários mais significativos da história moderna. De maneira avassaladora, o até então desconhecido Sars-CoV-2 difundiu-se por todo o planeta, ceifando vidas, potencializando o desequilíbrio socioeconômico, punindo parcelas mais precarizadas da sociedade e despertando um "medo" já um pouco esquecido. Na última vez em que a mídia foi inundada por boletins epidemiológicos, imagens desesperadoras de pessoas sem acesso aos serviços básicos e pela busca de uma "cura", o Brasil ainda vivia nas sombras de uma ditadura. Em $1980^{1}$ o primeiro caso brasileiro de Aids é notificado. É o início do que seria a maior epidemia do século XX no país.

A situação do HIV no Brasil mudou muito desde então. Elogiado internacionalmente por sua política de prevenção e tratamento, com disponibilização da terapia antirretroviral (TARV) em grande escala e de forma gratuita por meio do Sistema Único de Saúde (SUS), o país conseguiu diminuir de forma consistente a mortalidade da Aids e a transmissão do HIV. Dados do Boletim Epidemiológico da Secretaria de Vigilância em Saúde, divulgado em 2020, mostram que entre 2009 e 2019 a taxa de detecção de Aids caiu 17,2\%, ou seja, passamos de 21,5 para 17,8 casos por 100 mil habitantes. Dentro do mesmo período, a queda na mortalidade relacionada ao HIV/Aids, com base no coeficiente de mortalidade padronizado, foi de 29,3\%. Assim, também passamos de 5,8 para 4,1 óbitos a cada 100 mil habitantes.

1 Segundo dados do Departamento de Vigilância, Prevenção e Controle das IST, do HIV/Aids e das Hepatites Virais, São Paulo registra o primeiro caso brasileiro de Aids em 1980, classificado apenas em 1982. Disponível em: http://www.aids.gov.br/pt-br/noticias/ historia-da-aids-1980. Acesso em: 20 jan. 2021. 
Dados referentes à faixa etária dos 15 aos 24 anos nos ajudam a vislumbrar a vulnerabilidade, e consequente precarização da vida, da população jovem. Destacamos abaixo a interseccionalidade da situação de vulnerabilidade que se encontram determinados indivíduos, em especial aqueles e aquelas que possuem os recortes de gênero e sexualidade.

As vulnerabilidades específicas às múltiplas expressões de masculinidades em homens cis gêneros e à homossexualidade cis masculina, já amplamente escrutinadas (ANTUNES et al., 2002; GOMES, 2008; TAQUETE, 2009) ficam evidentes nas estatísticas mais recentes. Enquanto, de 2009 para 2019, na faixa etária dos 15 aos 19 anos, a taxa de detecção de Aids em mulheres caiu de 4,9 para 2,9 casos a cada 100 mil habitantes, entre homens essa taxa passou de 3,7 para 6,1 casos. Na faixa etária dos 20 aos 24 anos com marcador "mulheres" também houve queda, passando de 15,2 para 9,4 casos. No entanto, sob o marcador "homens" e dentro da mesma faixa etária, a taxa passou de 20,6 em 2009 para 36 casos em 2018. Um aumento de 74,8\% no período de uma década.

Em relação ao coeficiente de mortalidade relacionado à Aids, homens jovens de 20 a 24 anos, em conjunto com o grupo com 60 anos ou mais de ambos os sexos, se destacam por serem os únicos recortes a terem apresentado um aumento. Os números subiram, passando de 3,0 óbitos em 2009 para 3,3 óbitos a cada 100 mil habitantes em 2019. No estado do Rio Grande do Sul (RS) são ainda mais preocupantes. A Secretaria de Estado da Saúde do Rio Grande do Sul (SES/ RS), por meio da Coordenação Estadual de IST/Aids, apresentou em 2018 a quarta publicação do Boletim Epidemiológico de HIV/Aids. Segundo esse boletim, o Rio Grande do Sul: "no que se refere à idade, verifica-se que a maioria dos casos de infecção pelo HIV encontra-se na faixa etária de 25 a 29 anos, com percentual de $16,8 \%$. No total dos casos, $60,1 \%$ se concentram no grupo dos 20 aos 39 anos" (2018, p. 14).

Frente a tais índices propomos, no presente artigo, uma discussão sobre pedagogias da prevenção e suas articulações com a comunicação em saúde do Dezembro Vermelho, ou Dia Mundial de Combate à HIV/Aids, olhando para os possíveis diálogos e (des)encontros com as culturas juvenis. Para isso, foram selecionadas cinco do que chamamos de iniciativas influenciadoras $^{2}$ - canais, vídeos e seus respectivos níveis de engajamento - veiculadas na plataforma de compartilhamento de vídeos YouTube, entre os dias 27 de novembro e 7 de dezembro de 2020.

Com o objetivo de realizar uma análise cultural descritiva, entrelaçada às narrativas veiculadas sobre HIV/Aids na plataforma, esse texto se subdivide entre: "Culturas juvenis em (des) encontros" - tópico destinado a uma primeira discussão sobre juventude, enquanto uma categoria plural, e seus (des)encontros com demais marcadores como gênero, classe e etnia; "O YouTube e as narrativas do dezembro vermelho de 2020" - espaço em que discorremos sobre o conceito de narrativas e sobre a escolha metodológica pela plataforma de vídeos YouTube enquanto universo de pesquisa; e "Entre múltiplas iniciativas' - parte na qual realizamos uma análise em blocos das iniciativas selecionadas e aglutinadas de acordo com os formatos/linguagens empregadas em cada vídeo, sendo elas (a) Campanhas; (b) As experiências do EU; (c) O humor e os memes.

Utilizamos de marcadores conceituais como engajamento, solidariedade, empoderamento, de forma a investigar os sentidos empreendidos nas comunicações vinculadas ao HIV/Aids junto às multiplicidades, tanto daquilo que é característico das linguagens utilizadas no YouTube, quanto às especificidades dos contextos culturais nos quais as iniciativas estão inseridas.

2 Segundo Issaaf Karhawi, influenciadores "são aqueles que têm algum poder no processo de decisão de compra de um sujeito; poder de colocar discussões em circulação; poder de influenciar em decisões em relação ao estilo de vida, gostos e bens culturais daqueles que estão em sua rede" (KARHAWI, 2017, p. 2). Neste sentido, utilizamos e entendemos por iniciativas influenciadoras não só indivíduos, mas o conjunto de ações, produção de conteúdos, engajamentos e repercussão destes trabalhos e atividades. 


\section{Culturas juvenis em (des)encontros}

Para o Estatuto da Criança e do Adolescente (ECA) são considerados adolescentes aqueles e aquelas que têm entre 12 anos completos e 18 anos. Já para o Estatuto da Juventude, legislação organizada posteriormente (2013), são consideradas jovens as pessoas com idade entre 15 (quinze) e 29 (vinte e nove) anos de idade, marco etário que também é utilizado pela Secretaria Municipal de Juventude de Porto Alegre (RS) ${ }^{3}$. Para as declarações organizadas pelas Nações Unidas são jovens aqueles e aquelas que têm entre 15 e 24 anos como jovens. ${ }^{4}$ Frente aos discursos legais que marcam diferenças etárias a fim de "categorizar quem são os jovens", compreendemos, neste texto, o conceito de juventude como categoria plural, afastando-nos de um modo único para descrevê-la e contextualizá-la.

Estudos como os de Feixa (1999) e Dayrell, Carvalho e Geber (2012) distanciam-se das classificações etárias e descrições biológicas na contextualização da categoria juventude. Para Dayrell e demais autores (2012), a juventude pode ser considerada uma categoria dinâmica, atravessada pelas mudanças e transformações que ocorrem ao longo da história nas diversas sociedades. O referido autor compreende também que tal categoria é marcada pela diversidade, expressa nas diferenças sociais e culturais que constituem as posturas dos jovens. A partir dessa premissa, entendemos que a categoria juventude poderia ser pensada frente aos seus (des)encontros com demais marcadores como gênero, classe e etnia, os quais também (re)estabelecem definições sobre os limites de quem são/como agem os jovens, o que nos afasta ainda mais das delimitações apenas etárias.

Como pontua Vargas (2015, p. 42), o termo cultura juvenil é construído por Feixa (1999) a fim de destacar o "modo como as experiências sociais dos jovens são expressas coletivamente frente à construção/articulação de estilos de vida diferentes, observando que tais estilos são produzidos nos espaços de tempo livre ou nos 'interstícios' da vida institucional” dos jovens. Ou seja, as culturas juvenis são constituídas nos espaços de tempo livre dos jovens - aqueles não ordenados por instituições como família, escola, trabalho ou ainda, por práticas religiosas. Dessa forma, podemos pensar que a web, em especial, as redes sociais e as plataformas de interação e entretenimento como o YouTube sejam também espaços contemporâneos para os (des)encontros das culturas juvenis.

Feixa em entrevista para Oliveira e demais autores (2018) destaca amplitude das culturas juvenis na (re)construção dos modos de viver dos jovens, uma vez que tais culturas não se restringem às identificações com estilos musicais e/ou correntes ideológicas. A própria organização do mundo virtual, como "um grande cardápio" que permite múltiplas identificações, com diferentes estilos e ideias, fomenta a aproximação de jovens com distintas expressividades. Assim "hoje não estamos falando somente de minorias, as chamadas tribos urbanas, [...] as culturas juvenis hoje afetam todas as juventudes, ou seja, os jovens estão vivendo, envolvendo-se e participando de algum tipo de cultura juvenil" (OLIVEIRA et al., 2018, p. 317).

\section{O YouTube e as narrativas do Dezembro Vermelho de 2020}

Pensar nas discussões sobre HIV/Aids no campo das redes sociais, aqui especificamente no YouTube, enquanto narrativas que se "(des)encontram" nos permite um olhar mais apurado sobre os processos de construção, intencionalidades, conflitos e negociações envolvidos nas dinâmicas que ali começam e transbordam.

Ao esbarrar em perguntas básicas da análise, como "o que está sendo dito? Por quem está sendo dito? E como está sendo dito?", no campo da pesquisa com HIV/Aids, nos deparamos com questões

3 Ver: http://www2.portoalegre.rs.gov.br/smj/. Acesso em: 28 jan. 2021.

4 Ver: https://pt.unesco.org/fieldoffice/brasilia/expertise/youth-brasil. Acesso em: 28 jan. 2021. 
próprias dessa epidemia que em $2021 \mathrm{faz} 40$ anos $^{5}$. Os contextos, temporalidades, marcadores de gênero, raça, classe e sexualidade dizem tanto quanto os discursos médicos sobre a epidemia, pois a partir desses, múltiplas vulnerabilidades produzem diferentes respostas às estratégias de prevenção.

Segundo Onocko-Campos et al., "no âmbito das pesquisas qualitativas, os objetos de estudo se caracterizam como complexos, na medida em que remetem a problematizações sobre a atividade humana, considerando seus diferentes contextos e momentos históricos" (ONOCKO-CAMPOS et al., 2013, p. 2848). E assim, ao situarmos esta pesquisa enquanto uma análise qualitativa das narrativas - que estiveram presentes nas comunicações do Dezembro Vermelho, ou Dia Mundial de Combate à HIV/Aids, veiculadas no YouTube em 2020 - a complexidade toma forma.

Ainda a partir das discussões sobre narrativas - em diálogo com a filosofia de Paul Ricoeur (1994), a perspectiva histórica em Walter Benjamin (apud GAGNEBIN, 2004) e o campo da antropologia médica constituída a partir da fenomenologia - propostas por Onocko-Campos et al. (2013), nos deparamos com a dimensão do viver corporificado. Para Onocko-Campos e demais autoras e autores, produto desse corpo em situação,

Esta dimensão lhe atribui uma qualidade antes não percebida. O reconhecimento de uma diferenciação possível entre o conhecimento através do qual se vive a vida e o conhecimento através do qual a explicamos abre a possibilidade de considerar que as narrativas não sejam todas e sempre 'explicações' sobre a vida. (ONOCKO-CAMPOS et al., 2013, p. 2853).

O recorte metodológico apoiado em vídeos do YouTube possibilitou enxergar as nuances nas construções discursivas e narrativas a partir da experiência, afinal, se tratando de HIV/Aids, há sempre presente um elemento temporal no que está sendo dito. As atualizações e alterações nas linguagens e formas de abordar discussões associadas ao HIV/Aids, que periodicamente ocorrem, hoje estão registradas em um acervo on-line construído a muitas vozes.

Para Silva e Gomes, "a possibilidade de usar o site de compartilhamento de vídeos para expressar a sorologia em primeira pessoa permite a análise de questões históricas e discursivas relacionadas ao vírus" (SILVA; GOMES, 2020, p. 867). Isto, somado a participação cada vez maior de instituições públicas - como o Ministério da Saúde e o Departamento de Doenças Crônicas e IST - faz do YouTube um campo vasto para investigações e (des)encontros múltiplos entre aqueles e aquelas que têm o dever de falar e aqueles e aquelas que não estão escutando por inúmeros motivos. De acordo com o autor e a autora,

A narrativa em rede de pessoas vivendo com o vírus aproxima-se, em sua forma, do processo terapêutico, mas também traz características de um projeto de educação em saúde sexual que pode alinhavar militância, vigilância e entretenimento. Neste caso, uma proposta de informação para prevenção a riscos ligada a um cuidado de si, que é percebida ostensivamente no discurso dos youtubers que reafirmam a ausência de informações para o jovem na faixa mais vulnerável para novas infecções, entre os 15 anos e 24 anos. (SILVA; GOMES, 2020, p. 864).

Portanto, as cinco iniciativas (Quadro 1), selecionadas para o recorte das narrativas e discursos empreendidos em torno do HIV/Aids em uma das maiores datas sobre a temática, proporcionam um vislumbre das relações, marcadores e vulnerabilidades associadas às comunicações com culturas juvenis. Com olhar atento aos objetivos e metodologia, chegamos, enfim, às análises propriamente ditas, a descrição crítica e suas interlocuções com as categorias analíticas propostas.

5 De acordo com Silva e Gomes, no dia 5 de junho de 1981 o Centro de Controle e Prevenção de Doenças dos Estados Unidos (CDC) publicou o comunicado em seu Relatório Semanal de Morbidade e Mortalidade (MMWR) sobre casos de uma infecção pulmonar em cinco jovens gays, brancos, previamente saudáveis, moradores de Los Angeles [...] Esse teria sido o primeiro relato oficial do que seria conhecido como pandemia de Aids. (SILVA; GOMES, 2020, p.859). 
Quadro 1 - Youtube - Dezembro Vermelho 2020

\begin{tabular}{|c|c|c|c|c|}
\hline Canal & Inscritos & Vídeo & Data & Visualizações \\
\hline $\begin{array}{l}\text { Secretaria da } \\
\text { Saúde RS }\end{array}$ & $1,61 \mathrm{mil}$ & $\begin{array}{l}1^{\circ} \text { de dezembro - Dia Mundial de } \\
\text { Combate à Aids }(2 \mathrm{~min} 4 \mathrm{~s})\end{array}$ & $\begin{array}{l}1 \text { de dez. de } \\
2020\end{array}$ & 51 \\
\hline Léo Cezimbra & $20,7 \mathrm{mil}$ & $\begin{array}{l}\text { HIV/Aids - Por que continuamos } \\
\text { lutando? - Dezembro Vermelho| } \\
\text { Léo Cezimbra ( } 3 \text { min6s) }\end{array}$ & $\begin{array}{l}7 \text { de dez. de } \\
2020\end{array}$ & 223 \\
\hline $\begin{array}{l}\text { Lucas Raniel - } \\
\text { Falo memo! }\end{array}$ & $16,8 \mathrm{mil}$ & $\begin{array}{l}\text { Dezembro é o mês de falar de HIV, e } \\
\text { eu falo memo! Porque? (6min33s) }\end{array}$ & $\begin{array}{l}27 \text { de nov. de } \\
2020\end{array}$ & 467 \\
\hline Diego Krausz & $24 \mathrm{mil}$ & $\begin{array}{l}\text { Papo com Drew Persi (HIV+) } \\
(14 \mathrm{~min} 44 \mathrm{~s})\end{array}$ & $\begin{array}{l}3 \text { de dez. de } \\
2020\end{array}$ & 302 \\
\hline Põe na Roda & $1,2 \mathrm{mi}$ & $\begin{array}{l}\text { Afinal, PrEP aumenta outras ISTs } \\
\text { ou não? A verdade! - Põe Na Roda } \\
(16 \text { min22s) }\end{array}$ & $\begin{array}{l}1 \text { de dez. de } \\
2020\end{array}$ & 57.186 \\
\hline
\end{tabular}

Fonte: Elaborado pelos autores.

\section{Entre múltiplas iniciativas: Campanhas}

O primeiro vídeo deste bloco de análise, o intitulado 1o de dezembro - Dia Mundial de Combate à Aids ${ }^{6}$, apresenta a secretária Arita Bergmann - uma mulher branca de aproximadamente 70 anos de idade - toda vestida de branco com um pin boton no formato de um laço de fita vermelha (símbolo luta contra a Aids) em frente a um painel com os dizeres: "Contra a COVID, use máscara. Contra a Aids e outras ISTs, use camisinha” em letras de grafite.

Em seu discurso, a secretária diz: "A população, em especial, os nossos jovens, podem e devem ter consciência da importância do cuidado com a sua saúde. Então uma das atividades que vamos desenvolver é uma ampla campanha, em todas as mídias possíveis, mostrando, para o público jovem, a importância do autocuidado. Mostrando também que ele deve ter comportamentos responsáveis, como o uso do preservativo" (0:18). Ao finalizar, ela completa: "É o Rio Grande do Sul promovendo e fazendo novas façanhas" (1:49), fazendo referência ao hino do Estado.

Em termos de juventude é perceptível que se faz uma tentativa de apropriação de elementos considerados pertencentes às culturas juvenis. O grafite que compõe o painel de fundo, no entanto, contrasta com a figura e o figurino da secretária - que muito lembra os jalecos utilizados por profissionais da saúde.

Esse cenário, aliado a um discurso de cunho autoritário, que se posiciona enquanto detentor dos saberes e indicador dos comportamentos adequados à conduta da população jovem, não possibilita a construção de diálogos e culpabiliza tal população, partindo do pressuposto que eles "devem ter" (e não têm ainda) consciência acerca dos cuidados com sua saúde. Além disso, podemos observar uma narrativa que foca nos cuidados biomédicos, abrindo mão de discutir os aspectos culturais, econômicos, sociais e psicológicos que envolvem a prevenção ao HIV/Aids. Em trabalho recente sobre as representações da prevenção ao HIV/Aids em cartazes sobre o Dezembro Vermelho (LERMEN et al., 2020) é evidenciado o foco das campanhas institucionais na autovigilância, na responsabilização individual e na medicalização: "meios que acabam apagando ou eclipsando aspectos sociais e simbólicos caros ao enfrentamento da epidemia" (LERMEN et al., 2020, p. 14).

Tal narrativa institucional - representada aqui pela campanha da Secretaria da Saúde do RS - reforça um distanciamento já bastante familiar e problemático em relação às comunicações

6 Secretaria da Saúde RS. 1o de dezembro-Dia Mundial de Combate à Aids (2 min 04 s). Disponível em: https://youtu.be/4uMdtNkw8xE. Acesso em: 11 jan. 2020. 
produzidas e destinadas à juventude, em seus mais diversos contextos. Uma comunicação caracterizada por várias fissuras, que comprometem a efetividade de possíveis estratégias aliadas ao que Gavigan et al. (2015) chamaram de pedagogias da prevenção.

Segundo os autores e autoras, "a capacitação para a prevenção não significa apenas o processamento das informações, mas um processo de 'conscientização' e de empoderamento que permite às pessoas colocarem os conhecimentos em prática" (GAVIGAN et al., 2015, p. 13). Trata-se, portanto, de um esforço pedagógico que exige não só conscientização, como também a mediação para a "localização do 'eu' dentro do contexto social e ambiental da própria pessoa" (GAVIGAN et al., 2015, p. 13).

Desta forma, o que é possível perceber no vídeo é uma fala sem resposta, que se reflete nos números de engajamento: apenas 51 visualizações, nenhum "gostei", nenhum "não gostei". $\mathrm{O}$ contraste em relação aos dados de engajamento do vídeo produzido pela Secretaria da Saúde do RS com os demais vídeos selecionados para este artigo é um dos indícios da falta de assertividade nas campanhas de prevenção institucionais voltadas às culturas juvenis. Evidencia a fragilidade do aparato estatal em compreender o comportamento juvenil e empreender políticas públicas que se façam relevantes para essa população.

Imagem 1 - Captura de Tela (Secretaria da Saúde RS) - Vídeo 1

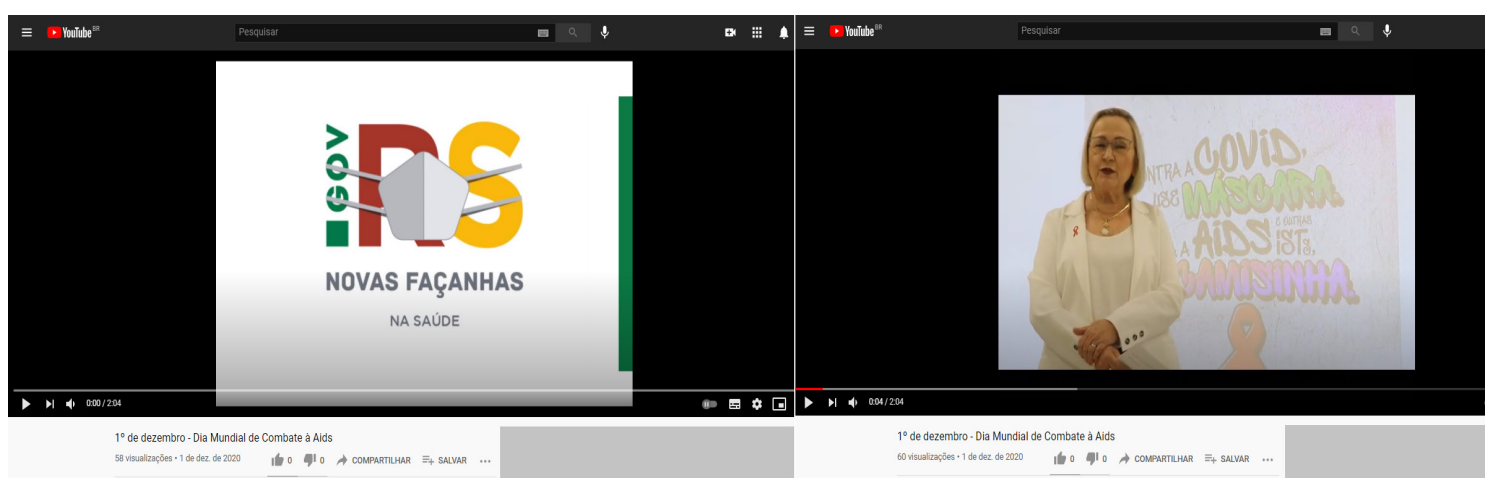

Fonte: Elaborado pelos autores

No canal Léo Cezimbra, o segundo vídeo que compõe este bloco foi publicado com o seguinte nome: HIV/Aids - Por Que Continuamos Lutando? - Dezembro Vermelho ${ }^{7}$. A iniciativa contou com a participação de 19 perfis engajados com discussões sobre saúde, sexualidade, HIV/Aids e outras Infecções Sexualmente Transmissíveis (ISTs). Na descrição do vídeo os seguintes dizeres:

Nós, pessoas de diferentes raças, credos, gêneros, orientações sexuais, regiões e sorologias, unimos nossas vozes para retomarmos a importância de LUTAR UNIDOS em prol de uma só CAUSA! "Lutar" não no sentido de ser um termo bélico, mas sim como um símbolo das ações de empenho e esforço por conquistas históricas na epidemia de Aids! Muitas pessoas vivendo com HIV/Aids antes de nós, lutaram para que direitos como acesso aos antirretrovirais fossem hoje garantidos de forma universal e gratuita no SUS. Perdemos muitos nesses longos anos, ainda continuamos perdendo, apesar de conquistarmos também alguns avanços, mas ainda seguimos em busca de uma resposta a essa epidemia. Hoje, após mais de 32 anos, poderíamos só ter resultados de conquistas nessa LUTA CONTRA A AIDS, mas muitos de nós ativistas, militantes, voluntários, YouTubers, mães, médicos e PVHA continuam nessa corrente de solidariedade, resiliência e respeito às pessoas que vivem com HIV ou Aids para que as estatísticas mudem; o acesso ao tratamento seja integral; direito algum seja perdido, que nossas vidas realmente importem! A luta continua, e vocês porque ainda Lutam Contra a Aids?

7 Léo Cezimbra. HIV/AIDS - Por Que Continuamos Lutando? - Dezembro Vermelho | Léo Cezimbra (3 min 6 s). Disponível em: https:// youtu.be/oEnh1JyVxXA. Acesso em: 13 jan. 2020. 
O vídeo começa com uma tela vermelha e pergunta: “Pelo que você luta?". Logo depois, diversas pessoas aparecem sequencialmente em gravações curtas e conectadas pela passagem do símbolo de luta contra a Aids (o laço de fita vermelha). Dando seu relato e expressando seus desejos quanto a conquistas e mudanças de paradigmas relacionados às experiências de pessoas que vivem e convivem com HIV/ Aids, diversos temas e contextos são acionados. Entre gravidez, segurança, privação de liberdade, violência, Igreja, juventude, papel do Estado, negritude e acesso à informação, os tópicos dialogam com a importância de se pensar a agência que questões como raça, classe, sexualidade, religião e gênero têm sobre as agendas e políticas públicas de enfrentamento a epidemia de HIV/Aids.

Em suas redes sociais, Léo Cezimbra caracteriza suas produções e matérias como: "Confissões de uma pessoa vivendo com HIV e seus passos para compreender sua nova condição + informação sobre HIV/Aids, saúde e temática LGBTQI+". Esse tipo de posicionamento tem se tornado cada vez mais comum nas redes sociais, fazendo com que a temática não fique restrita às vozes de profissionais da saúde e instituições governamentais.

Apesar de esse tipo de conteúdo não gerar tanto engajamento quanto outros canais de entretenimento, é notável como há uma outra linguagem e abordagem ao HIV/Aids nestes canais. Ao produzirem conteúdos a partir da própria experiência e utilizando linguagens próprias das culturas juvenis - como os memes - elementos como identificação e proximidade à realidade social, tais materiais parecem gerar uma melhor aceitação por parte da comunidade do que peças publicitárias. Afirmamos isso frente a uma grande diferença no número de visualizações em comparação com canais institucionais como o da Secretaria da Saúde RS.

Imagem 2 - Captura de Tela (Léo Cezimbra) - Vídeo 2

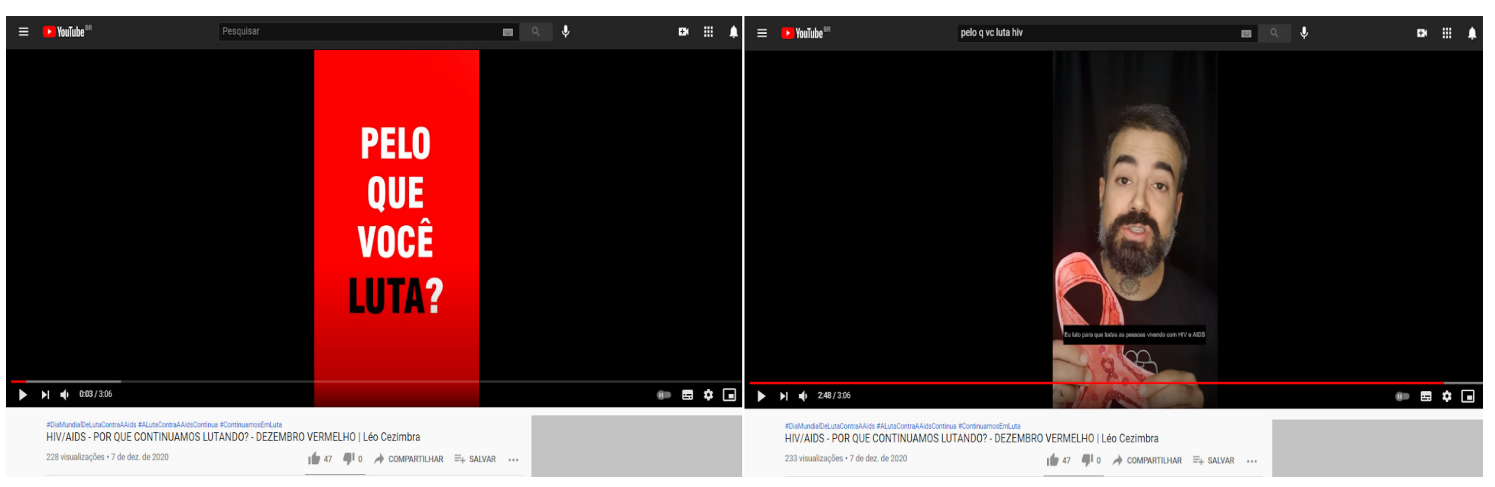

Fonte: Elaborado pelos autores.

\section{Entre múltiplas iniciativas: as experiências do EU}

No vídeo Dezembro é o Mês de falar de HIV, e eu falo Memo! Porquê??, o primeiro deste bloco, Lucas Raniel aparece em um cômodo, do que aparenta ser a sua casa, com uma bandeira LGBTQIA ${ }^{9}$ ao fundo, indicando seu pertencimento aos grupos de pessoas não heterossexuais e/ou cisgêneras.

\footnotetext{
8 Lucas Raniel. Falo memo! Dezembro é o Mês de falar de HIV, e eu falo Memo! Porque? (6 min 33 s). Disponível em: https://youtu. be/G_0CZrW897Q. Acesso em: 25 jan. 2020.

9 Ao longo dos anos, os movimentos LGBTQIA+ reivindicaram e atualizaram uma série de elementos simbólicos às suas lutas, experiências e demandas. Entre siglas, símbolos, bandeiras, frases e palavras de ordem, existem diversas variações do que é considerado enquanto representativo LGBTQIA+. Neste caso específico, a bandeira em questão é conhecida por "Bandeira Progressista do Orgulho LGBTQIA+" e é assinada por Daniel Quasar - artista que se identifica como queer e não-binário. Nela, as cores branco, rosa e azul claro, que representam a comunidade trans, e as cores marrom e preto, que representam as pessoas pretas e vítimas do HIV, são somadas às conhecidas cores do arco-íris.
} 
Na descrição de seu canal o seguinte texto traz elementos e tópicos de discussão, que guiam as narrativas presentes na maioria de seus vídeos:

E ai galera beleza?! Meu nome é Lucas Raniel. Vamo lá, vou ser direto: eu acredito que existam muitas informações sobre HIV que vocês talvez não tiveram acesso por conta de várias questões que eu também vou explicar pra vocês aqui no canal ao decorrer do tempo. Pra quem não me conhece pelo Instagram ainda, vamos lá: EU VIVO COM HIV. Ta curiose? Se inscreve aí que a frequência de postagem acontecerá $1 \mathrm{x}$ por semana, e cada semana vou trazer um ponto, polêmico (ou não) pra falar memo pra vocês.

É perceptível pelo texto, por exemplo, o seu lugar de fala enquanto jovem e soropositivo, o que já distingue o canal daqueles em que médicos, instituições ou pessoas envolvidas com movimentos sociais e organizações não governamentais falam ou são convidados a falar sobre HIV/Aids. Esse, sem dúvidas, é um dos principais pontos que merecem destaque nas análises das narrativas com culturas juvenis em relação à sexualidade e HIV/Aids.

As iniciativas de prevenção institucionais prezam, na maioria das vezes, pelo olhar e narrativa do especialista, seja este um profissional da saúde ou simplesmente um adulto, mais "vivido" e "experiente", mesmo que esta experiência não tenha significado dentro das múltiplas vivências das culturas juvenis. A partir dos trabalhos de Moraes (2003) e Bastos (2004), Marilia Pontes Sposito (2009) sintetiza os limites apontados pelas autoras em relação às políticas de prevenção direcionadas aos jovens:

As experiências [de políticas públicas de prevenção voltadas a jovens] negligenciam um olhar específico para esse grupo social e suas demandas, ou, apesar do reconhecimento destas, o baixo orçamento e o despreparo técnico com os quais os projetos e programas se constituem acabam criando abismos entre diretrizes e ações. (SPOSITO, 2009, p. 246).

A expertise do jovem como multiplicador de informações relacionadas à saúde sexual (MORAES, 2003) ou como influenciador de seus pares é perdida, de modo geral, nas campanhas institucionais. Se, como afirmam Castro e Abramovay (2004), as conversas entre os pares gozam de uma posição privilegiada quando o assunto é a socialização dos jovens quanto à sexualidade, sabendo que as ações de prevenção empreendidas pelos governos na última década não demonstraram a mesma efetividade entre a faixa etária de 15 a 24 anos em comparação com a população mais velha, por que continuamos apostando numa perspectiva adulta e técnica na comunicação com as culturas juvenis?

Imagem 3 - Captura de Tela (Lucas Raniel - Falo memo!) - Vídeo 3

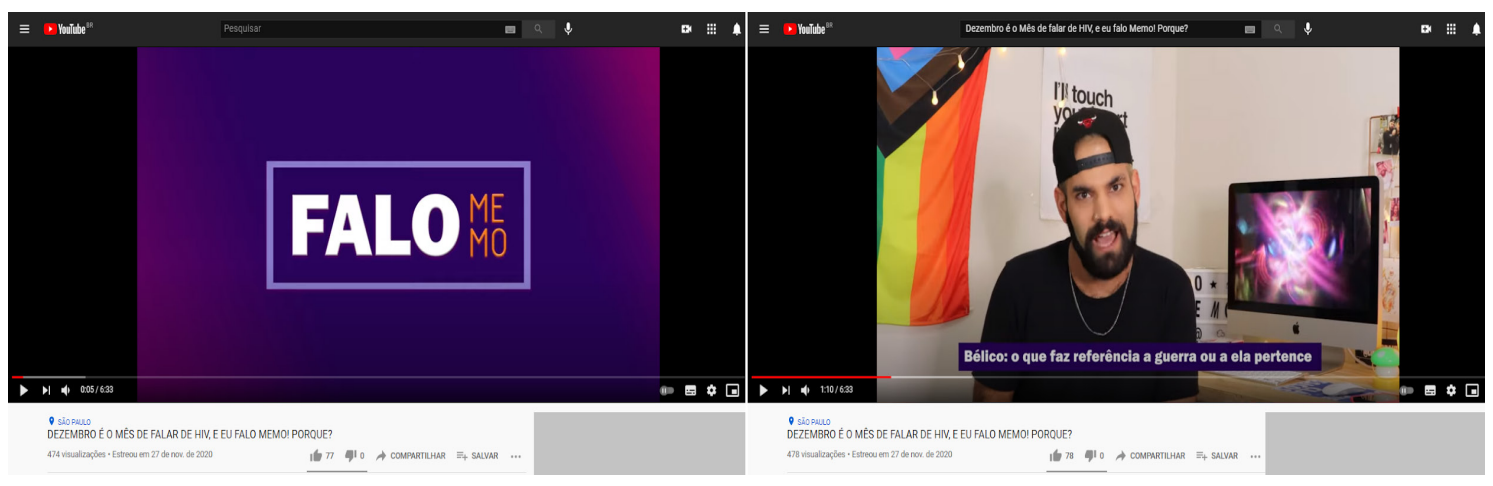

Fonte: Elaborado pelos autores. 
O canal de Diego Krausz pode ser definido como um canal de cultura pop, com vídeos do tipo reação ${ }^{10}$, reviews de filmes e álbuns musicais, além de relatos do dia a dia do youtuber. $\mathrm{O}$ ponto focal do canal é a temática da sexualidade, principalmente de cultura gay - já que Diego é um homem, cis, gay, branco. Além disso, muitos vídeos abordam, de forma aberta e muitas vezes bem-humorada, sua condição como pessoa HIV-positiva. O vídeo em questão, intitulado Papo com Drew Persi $(H I V+)^{11}$ consiste em uma conversa com o youtuber e escritor Drew Persi.

A principal temática abordada no canal de Drew é também sua condição como pessoa HIV-positiva, tanto em seus vídeos, como em seu livro, intitulado Vidas: Sobre todas as vezes que morri, para que pudesse nascer outra vez. ${ }^{12}$. O tema principal do vídeo são os aspectos afetivos, amorosos e de sociabilidade de pessoas, principalmente homens gays, HIV-positivas. A publicização de seus status em relação ao HIV é debatida pelos youtubers, numa avaliação após dois anos do vídeo em que os dois gravaram juntos tornando público seus status. Os ônus e bônus são elencados, apesar de o sentimento geral ser de aprovação à ideia de tornar público. O único ônus apresentado é um sentimento de invasão, potencializado por conta de seus trabalhos como influenciadores. A exposição e o fato de falarem sobre sexualidade e ISTs criam um sentimento de conexão com os seguidores e por parte deles. Assim, é comum pessoas que acompanham os vídeos e são HIV-positivas se sentirem à vontade em fazer perguntas indiscretas, ou colocar uma carga ou responsabilidade muito grande sobre ambos, ao recorrerem a eles em questões médicas ou psicológicas.

Os bônus referentes à publicidade se dividem em dois eixos: o coletivo e o individual. O eixo coletivo se aproxima do conceito de solidariedade, como abordado em Desperdício da experiência e precarização da vida: momento político contemporâneo da resposta brasileira à aids (SEFFNER; PARKER, 2016). Para os autores,

Solidariedade é uma estratégia de ação que acontece simultaneamente à busca da cura farmacêutica da aids, uma vacina de eficácia comprovada contra o que acabou por ser conhecido como 'terceira epidemia de aids', a epidemia da discriminação contra as pessoas vivendo com HIV/Aids. O exercício da solidariedade desloca a aids decididamente para o campo político, e permite envolver todos os tipos de pessoas na luta, e não apenas profissionais de saúde. (SEFFNER; PARKER, 2016, p. 296).

A troca de experiências com seus pares, o aconselhamento, o contato com outras realidades sociais e econômicas e, com pessoas vivendo diferentes níveis de precariedade podem ser uma ferramenta frutífera no entendimento de sua posição como indivíduo que é parte de uma comunidade. Isso pode, como citado por Drew, refletir positivamente em sua autoestima e no seu processo de enfrentamento aos estigmas. O eixo individual é formado pela ideia de liberdade, de quebra de barreiras e estigmas em publicizar. Existe uma forte conexão entre tornar público sua condição como HIV-positivo e o "sair do armário" da cultura LGBTQIA+. É a sensação de liberdade, de vencer os estigmas sociais enraizados em seu próprio ser, em sua própria consciência.

Além disso, também é possível dizer que o vídeo opera através do conceito de empoderamento, abordado, definido como: "a conquista dos meios para documentar a maneira pela qual os contextos sociais, a violência e a própria doença afetam as pessoas vivendo com HIV. Trata-se de transformar as pessoas HIV-positivas em donas do seu próprio tratamento" (GAVIGAN et al., 2015, p. 5).

\footnotetext{
10 Vídeos onde pessoas gravam sua reação a algum evento, filme, série, clipe musical, etc. Esse tipo de conteúdo ganhou relevância já nos primeiros anos do YouTube, por volta de 2006.

11 Diego Krausz. Papo com Drew Persi (HIV+) (14 min 44 s). Disponível em: https://youtu.be/ei6iffY-_34. Acesso em: 11 jan. 2020. 12 Lançado em 2020, o livro é descrito nos principais sites de acesso como uma autobiografia que "nos mostra a importância da resiliência, de se visitar um passado e fazer as pazes com ele [...] Um relato sincero de toda sua trajetória, desde a infância, os traumas da violência doméstica, os amores que o construíram, o diagnóstico de HIV positivo e a superação através da arte!".
} 
Imagem 4 - Captura de Tela (Diego Krausz) - Vídeo 4



Fonte: Elaborado pelos autores.

O número maior de inscritos e de visualizações de tais materiais frente aos vinculados ao vídeo promovido pela Secretaria de Saúde do RS, evidencia uma maior comunicabilidade de tais materiais para (e entre) os jovens. Tal fato poderia também, por conseguinte, acarretar uma possível melhoria nos índices de contaminação entre os jovens, uma vez que, possivelmente, muitos dos seguidores desses dois últimos canais sejam jovens.

\section{Entre múltiplas iniciativas: 0 humor e os memes}

A iniciativa influenciadora selecionada para este bloco de análise faz parte do acervo de vídeos do canal Põe Na Roda, um dos maiores canais em cultura gay e cultura pop em geral. As interações e engajamento neste canal, em especial, merecem certo destaque: com 1,2 milhão de inscritos no canal, o vídeo em questão, intitulado Afinal, PrEP aumenta outras ISTs ou não? A verdade! - Põe Na Roda $^{13}$, por exemplo, alcançou a marca de 58 mil visualizações.

\section{Imagem 5 - Captura de Tela (Põe na Roda) - Vídeo 5}

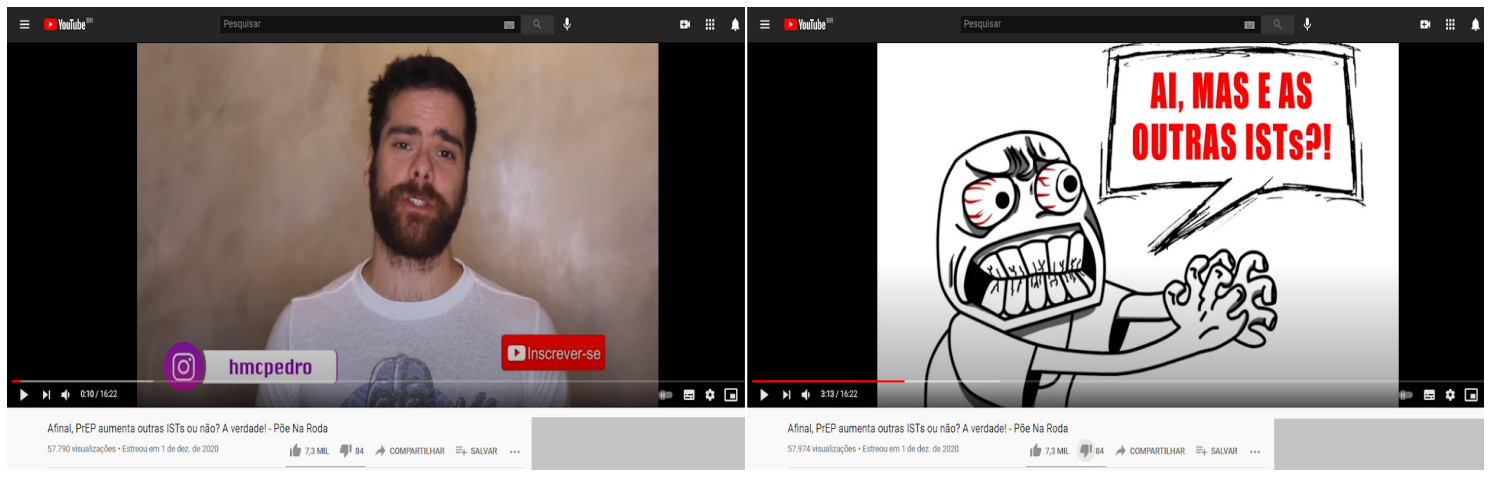

Fonte: Elaborado pelos autores.

Sendo as publicações semanais, os conteúdos do Põe na Roda - que em sua descrição coloca-se enquanto um local de humor e informação fora do armário - tratam dos mais diversos assuntos, relacionados à sexualidade e movimentos LGBTQIA+, utilizando do humor e da linguagem de memes. Segundo Souza,

No ciberespaço os 'memes' têm a ver principalmente com comentários, postagens de fotos, vídeos, paródias que são comumente relacionados a notícias do cotidiano provenientes em grande parte de outros canais midiáticos, sendo estes a televisão, os jornais impressos e o rádio. (SOUZA, 2013, p. 131).

13 Põe Na Roda. Afinal, PrEP aumenta outras ISTS ou não? A verdade! - Põe Na Roda (16 min 22 s). Disponível em: https://youtu.be/ UXin8LIpNOc. Acesso em: 27 jan. 2020. 
Conforme destaca em sua recente pesquisa, Fink (2020, p. 32), ancorado em autores como Jenkins, Green e Ford (2014), o humor no YouTube pode ser entendido como "técnica bem-sucedida em uso na plataforma [...] voltada a suscitar comentários que permitam ter-se dados acerca da recepção do público ao conteúdo apresentado". Logo, podemos depreender que o uso do humor através de sátiras e memes coloque-se como estratégia de aproximação entre o produtor (e do conteúdo) do canal e as juventudes contemporâneas.

Inicialmente, Pedro - um jovem adulto, cis, branco e gay - fornece uma série de dados sobre o uso da PrEP (Profilaxia pré-exposição) e sua relação com a diminuição do índice de transmissão do HIV. Intercalando a apresentação estatística com recordes de vídeos engraçados e montagens meméticas, os dados são utilizados para rebater o discurso de que o uso da PEP (Profilaxia Pós-Exposição de Risco) e da PrEP aumentam o índice de outras ISTs por conta da diminuição do uso da camisinha.

O discurso apresentado no vídeo está em consonância com o conceito de empoderamento (GAVIGAN et al., 2015) e com a promoção de práticas ligadas às pedagogias da prevenção. Segundo Pedro, a melhor maneira de potencializar a eficácia e a abrangência das políticas de prevenção é por meio da prevenção combinada em conjunto com o acesso à informação e aos dispositivos que a compõem. Assim, com o conhecimento e as informações devidamente elucidados, o jovem pode se tornar dono de sua prevenção, sendo capaz de optar pelos métodos que mais se adaptem ao seu contexto social e comportamento sexual.

Desta forma, o acesso aos dispositivos de cuidado e saúde precisaria vir acompanhado de novas pedagogias da prevenção, que instruam os jovens não apenas a utilizarem determinado dispositivo de forma impositiva, mas que os capacitem a decidirem, de forma consciente, tendo conhecimento de seus direitos, qual dispositivo utilizar. Conhecer seus hábitos sexuais e o funcionamento de seu corpo é primordial para uma maior adesão aos métodos de prevenção.

Para Tavares e Mesquita (2020, p. 566), é justamente no poder que os influenciadores digitais têm de "induzir o comportamento dos indivíduos, realizando de maneira indireta ações que possam estimular determinados comportamentos, utilizando diversas ferramentas para promover o engajamento de seus seguidores" que reside o potencial para estimular e promover educação sexual. Neste sentido, é possível perceber o quanto a adesão e interação da população jovem às políticas e iniciativas de combate à epidemia de HIV/Aids, promovidas por meio do universo digital, está diretamente relacionada às linguagens e formatos que se relacionam e (des)encontram as culturas juvenis - sejam elas campanhas, relatos de experiência ou mesmo edições humorísticas de conteúdo.

\section{Considerações Finais}

A partir da análise empreendida, é possível destacar que os vídeos analisados partilham de algumas estratégias semelhantes para a promoção de cuidados e prevenção à epidemia de HIV/ Aids. Tais iniciativas, costuradas a partir das narrativas de experiências/vivências junto ao vírus, às múltiplas sexualidades e identidades, por vezes, amenizadas por memes e "humor", acabam por "roteirizar", ordenar e circunscrever modos de ser e viver como jovem em meio ao HIV/Aids.

Não questionamos a aplicabilidade de tais práticas para a prevenção ao vírus e seus efeitos no controle da epidemia, porém problematizamos acerca da permeabilidade de tais práticas na "vida real" dos jovens. Também percebemos o distanciamento entre a campanha promovida pela Secretaria de Estado e as culturas juvenis contemporâneas. As juventudes são "chamadas" na campanha através de marcas presentes no cenário, mas não são promovidas a ter "voz" no referido espaço, uma vez que o lugar do saber e de promotora de boas práticas de prevenção, fica restrito à Secretária de Saúde. A aposta na narrativa medicalizante e de autovigilância, tendo o agente de saúde ou o adulto como detentores do saber, restringe o sujeito jovem a uma posição de mera aceitação (LERMEN et al., 2020). Esse posicionamento se afasta da noção de empoderamento, já abordada anteriormente. 
Entendemos como necessária a aproximação - nas campanhas institucionais - entre os múltiplos modos de ser e de viver dos jovens contemporâneos e os discursos e práticas por elas promovidos, a fim de que as estratégias de prevenção sejam também mais bem articuladas pelo Estado, em especial entre os jovens. Tal posição está de acordo com as proposições abordadas por Seffner (2018), que nos instigam a pensar as culturas juvenis como produtoras de informação, num exercício de experimentação de novas estratégias de prevenção. Lembremos o quão efetivo o Estado já se mostrou em outras dimensões da epidemia, a exemplo dos tratamentos que apresentamos no início do texto. Não seria também o momento de aproximação das práticas de prevenção e as culturas juvenis contemporâneas?

\section{Referências}

ANTUNES, Maria Cristina et al. Diferenças na prevenção da Aids entre homens e mulheres jovens de escolas públicas em São Paulo, SP. Revista de Saúde Pública, São Paulo, v. 36, n. 4, p. 88-95, 2002. Supl. 4. Disponível em: http://www. scielo.br/scielo.php?script=sci_arttext\&pid=S0034-89102002000500013\&lng=en\&nrm=iso. Acesso em: 25 jan. 2021.

BASTOS, Fernanda Graneiro. Interfaces e lacunas na assistência prestada ao adolescente convivendo com o HIV/AIDS. 2004. Dissertação (Mestrado em Serviço Social) - Universidade do Estado do Rio de Janeiro, Rio de Janeiro, 2004.

BRASIL. Lei no 8.069, de 13 de julho de 1990. Dispõe sobre o Estatuto da Criança e do Adolescente e dá outras providências. Diário Oficial [da] República Federativa do Brasil: Brasília, DF, 1990. Disponível em: http://www.planalto. gov.br/ccivil_03/leis/18069.htm. Acesso em: 28 jan. 2021.

BRASIL. Lei no 12.852, de 5 de agosto de 2013. Institui o Estatuto da juventude e dispõe sobre os direitos dos jovens, os princípios e diretrizes das políticas públicas de juventude e o Sistema Nacional de Juventude - SINAJUVE. Diário Oficial [da] República Federativa do Brasil: Brasília, DF, 2013. Disponível em: http://www.planalto.gov.br/ccivil_03/_ato20112014/2013/lei/l12852.htm. Acesso em: 28 jan. 2021.

BRASIL. Ministério da Saúde. Boletim Epidemiológico HIV/Aids 2020. Brasília, DF: Secretaria de Vigilância em Saúde, número especial, dez. 2020. Disponível em: http://www.aids.gov.br/pt-br/pub/2020/boletim-epidemiologico-hivaids-2020. Acesso em: 28 jan. 2021

CASTRO, Mary Garcia; ABRAMOVAY, Miriam, SILVA, Lorena Bernadete. Juventudes e Sexualidade. Brasília, DF: UNESCO Brasil, 2004.

DAYRELL, Juarez; CARVALHO, Levindo; GEBER, Saulo. Os jovens educadores em um contexto de educação integral. In: MOLL, Jaqueline. Caminhos da educação integral no Brasil: direito a outros tempos e espaços educativos. Porto Alegre: Penso, 2012. p. 157-171.

FEIXA, Carles. De jóvenes, banda y tribos:antropologia de la juventude. Barcelona: Ariel, 1999.

FINK, Tiago dos Santos. Vídeos da playlist "Ciência do Humor" do Canal Ciência em Show como pedagogias culturais. 2020. Dissertação (Mestrado em Educação) - Universidade Luterana do Brasil, Canoas, 2020.

GAGNEBIN, Jeanne Marie. História e narração em W. Benjamin. São Paulo: Perspectiva, 2004.

GAVIGAN, Kelly et al. Pedagogia da Prevenção: reinventando a prevenção do HIV no século XXI. Rio de Janeiro: Associação Brasileira Interdisciplinar de AIDS - ABIA, 2015. Disponível em: http://abiaids.org.br/wp-content/ uploads/2015/11/PolicyBrief_portugues_jan2016.pdf. Acesso em: 25 jan. 2021.

GOMES, Romeu. Sexualidade masculina, gênero e saúde. Rio de Janeiro: Editora Fiocruz, 2008.

JENKINS, Henry; FORD, Sam; GREEN, Joshua. Cultura da Conexão: criando valor e significado por meio da mídia propagável. Tradução Patrícia Arnaud. São Paulo: Aleph, 2014.

KARHAWI, Issaaf. Influenciadores digitais: conceitos e práticas em discussão. In: CONGRESSO BRASILEIRO CIENTÍFICO DE COMUNICAÇÃO ORGANIZACIONAL E RELAÇÕES PÚBLICAS, 11., 2017, Belo Horizonte. Anais eletrônicos [...] Belo Horizonte: Abrapcorp, 2017. p. 1-15. Disponível em: https://editora.pucrs.br/acessolivre/anais/ abrapcorp/assets/edicoes/2017/arquivos/15.pdf. Acesso em: 25 jan. 2021. 
LERMEN, Helena Salgueiro et al. Aids em cartazes: representações sobre sexualidade e prevenção da Aids nas campanhas de $1^{\circ}$ de dezembro no Brasil (2013-2017). Interface, Botucatu, v. 24, 2020. Disponível em: http://www.scielo.br/ scielo.php?script=sci_arttext\&pid=S1414-32832020000100205\&lng=en\&nrm=iso. Acesso em: 27 jan. 2021.

MORAES, Teresa Cristina Lara. Estudo de um programa de prevenção em DST/AIDS. 2003. Dissertação (Mestrado em Educação) - Universidade de São Paulo, São Paulo, 2003.

OLIVEIRA,Victor Hugo Nedel et al. Culturas juvenis e temas sensíveis ao contemporâneo: uma entrevista com Carles Feixa Pampols. Educar em Revista, Curitiba, v. 34, n. 70, p. 311-325, jul./ago. 2018. Disponível em: https://www.scielo. br/pdf/er/v34n70/0104-4060-er-34-70-311.pdf. Acesso em: 15. jan. 2021.

ONOCKO-CAMPOS, Rosana Teresa et al. Narrativas no estudo das práticas em saúde mental: contribuições das perspectivas de Paul Ricoeur, Walter Benjamim e da antropologia médica. Ciência \& saúde coletiva, Rio de Janeiro, v. 18, n. 10, p. 2847-2857, out. 2013. Disponível em: http://www.scielo.br/scielo.php?script=sci_arttext\&pi$\mathrm{d}=$ S1413-81232013001000009\&lng=pt\&nrm=iso. Acesso em: 22 jan. 2021.

RICOEUR, Paul. Tempo e narrativa. Tomo I. Campinas: Papirus Editora, 1994.

RIO GRANDE DO SUL. Secretaria de Estado da Saúde. Departamento de Ações em Saúde. Seção Estadual de Controle das DST/Aids. Boletim Epidemiológico: HIV/Aids. Porto Alegre: Secretaria de Estado da Saúde/Escola de Saúde Pública, 2019. Disponível em: https://saude.rs.gov.br/upload/arquivos/201910/30120845-boletim-epidemiologico-hiv-aids-rs-2018-versao-online-final.pdf. Acesso em: 28 jan. 2021.

SEFFNER, Fernando. Pedagogias e políticas no campo da AIDS: o desafio de superar o desperdício da experiência e reinventar a prevenção. In: LEITE, Vanessa; TERTO JÚNIOR, Veriano; PARKER, Richard (org). Dimensões Sociais e Políticas da Prevenção. Rio de Janeiro: Associação Brasileira Interdisciplinar de AIDS - ABIA, 2018. p. 10-15.

SEFFNER, Fernando; PARKER, Richard. Desperdício da experiência e precarização da vida: momento político contemporâneo da resposta brasileira à aids. Interface, Botucatu, v. 20, n. 57, p. 293-304, jun. 2016. Disponível em http://www. scielo.br/scielo.php?script=sci_arttext\&pid=S1414-32832016000200293\&lng=pt\&nrm=iso. Acesso em: 22 jan. 2021.

SILVA, Phelipe Rodrigues da; GOMES, Isaltina Mello. Disputas pela significação no discurso do HIV/aids: um percurso na ciência, na literatura, na militância LGBTI e nos canais do YouTube. RECIIS: Revista Eletrônica de Comunicação, Informação \& Inovação em Saúde, Rio de Janeiro, v. 14, n. 4, p. 857-869, out./dez. 2020. Disponível em: https://www. reciis.icict.fiocruz.br/index.php/reciis/article/view/2199. Acesso em: 22 jan. 2021.

SOUZA, Carlos Fabiano de. Memes: formações discursivas que ecoam no ciberespaço. Vértices, Campos dos Goitacazes, v. 15, n. 1, p. 127-148, jan./abr. 2013. Disponível em: https://www.researchgate.net/publication/266617279_Memes_formacoes_discursivas_que_ecoam_no_ciberespaco. Acesso em: 25 jan. 2021.

SPOSITO, Marilia Pontes (coord.). Estado da Arte sobre juventude na pós-graduação brasileira: educação, ciências sociais e serviço social (1999-2006). Belo Horizonte: Argvmentvm, 2009. v. 1.

TAQUETE, Stella Regina (org.). Aids e juventude: gênero, classe e raça. Rio de Janeiro: Eduerj, 2009.

TAVARES, Ronielisson Loiola de Jesus; MESQUITA, Fabiana Elias de. Youtubers: potencial de contribuição na educação sexual. RPGE: Revista online de Política e Gestão Educacional, Araraquara, v. 24, n. 2, p. 554-570, maio/ago. 2020. Disponível em: https://periodicos.fclar.unesp.br/rpge/article/view/13692/9086. Acesso em: 29 jan. 2020.

VARGAS, Juliana Ribeiro de. O que ouço me produz e me conduz? A constituição de feminilidades contemporâneas de jovens contemporâneas no espaço escolar da periferia. 2015. Tese (Doutorado em Educação) - Universidade Federal do Rio Grande do Sul, Porto Alegre, 2015.

Data de submissão: 29/01/2021

Data de aceite: 09/02/2021 